\title{
UTRICULARIA UXORIS (LENTIBULARIACEAE), UNA NUEVA ESPECIE COSTARRICENSE DE LA SECT. ORCHIDIOIDES
}

\author{
JoRGe GómEz-LAURITO \\ Escuela de Biología, Ciudad Universitaria 2060, San José, Costa Rica. \\ Investigador Asociado, Dept. of Botany, Field Museum of Natural History, Chicago, U. S. A.
}

\begin{abstract}
A new species of Utricularia (Lentibulariaceae) sect. Orchidioides is described and illustrated in this paper. U. uxoris is distinguished by its small, delicate habit, and tiny, glabrous, green flowers with a white spur.
\end{abstract}

Resumen. Una nueva especie de Utricularia (Lentibulariaceae), sect. Orchidioides, se describe y se ilustra en este artículo. U. uxoris se distingue por su hábito delicado, de corta estatura, y sus flores pequeñas, glabras y de color verde, con la espuela blanca.

\section{Palabras clave / Kew words: Lentibulariaceae, Utricularia, Utricularia uxoris, Costa Rica}

Al menos 11 especies del género Utricularia L. (Lentibulariaceae) han sido encontradas hasta el presente en Costa Rica (Crow 1992, Taylor 1989); cuatro de estas especies pertenecen a la Sect. Orchidioides A. DC., que consta en total de nueve especies distribuidas en América Central, Antillas y América del Sur. Las plantas de este grupo se caracterizan por ser epífitas o terrestres con hojas enteras, no divididas en segmentos, tubérculos presentes, flores blancas, rosado azuladas o rojas, lóbulos del cáliz iguales, espuela de la corola más corta o igual al labio inferior, o bien muy desarrollada excediendo en mucho al labio inferior y fuertemente curvada. A continuación se describe una nueva especie costarricense de esta sección:

\section{Utricularia uxoris Gómez-Laur., sp. nova}

Tipo: Costa Rica. Cartago. Jiménez. Pejibaye. Selva. Reserva Biológica El Copal. Sendero Tigre. $09^{\circ} 46^{\prime} 48^{\prime \prime} \mathrm{N}, 83^{\circ} 45^{\prime} 19^{\prime}$ 'O, 1080 m, 23 oct 2004 (fl, fr), J. Gómez-Laurito 14360, Diego Salazar \& Jorge Carmona (Holotipo: USJ, isotipos: CR, F).

Fig. 1.

A speciebus quas $A$. de Candolle ad sectionem Orchidioides ascripsit combinatione statura minore, floribus viridibus, glabris, calcare albo facile distinguenda.

Plantas delicadas, epífitas, $3-16 \mathrm{~cm}$ (in vivo ca. $20 \mathrm{~cm}$ ) de alto, glabras. Rizoides ausentes. Estolones filiformes, hasta $3 \mathrm{~cm}$ de largo, 0.3-0.5 $\mathrm{mm}$ de grosor, tubérculos elipsoides, 3-5 $\mathrm{mm}$ de largo. Trampas en estolones y ramas de los estolones, 0.5-0.8 $\mathrm{mm}$ de diámetro, globoso-comprimidas, hialinas, estipitadas (estípite ca. $0.8 \mathrm{~mm}$ de largo), el poro basal, con 2 diminutos apéndices subulados y recurvados a cada lado. Hojas 1
(2), originándose de la base del pedúnculo, pecioladas, lámina 30-40 x 5-8 mm, angostamente elíptica, cuneada y decurrente en la base, aguda en el ápice. Inflorescencia erecta, simple, 3-19 $\mathrm{cm}$ de largo; pedúnculo $\mathrm{ca} .0 .8$ $\mathrm{mm}$ de grueso, glabro. Escamas 2, basifijas, ca. $2 \mathrm{~mm}$ de largo, angostamente lineares, el ápice subagudo. Brácteas basifijas, angostamente ovadas, $c a .3 \mathrm{~mm}$ de largo. Bracteolas en verticilos de 3, 4-5 mm de largo, glabras. Pedicelo 10-12 $\mathrm{mm}$ de largo, terete, filiforme, ca. $0.5 \mathrm{~mm}$ de grosor, recto o subrecto, glabro. Flores 1-3, 4-6 mm de largo. Cáliz con lóbulos anchamente ovados, redondeados en ápice y base, nervados, verdes en antesis. Corola verde pálido, 4-5 $\mathrm{mm}$, labio superior semicircular, más pequeño que el cáliz, los márgenes glabros, erosos, involutos, labio inferior cuneado, redondeado en el ápice con 3 lóbulos apenas insinuados, lóbulos $0,5 \mathrm{~mm}$, anchamente oblongos, margen irregular, eroso; espuela subulada desde una base cónica, ápice agudo, curvada hacia arriba, hirsuta con pelos simples, blanca, más larga que el lóbulo inferior. Estambres 2. Filamentos $c a .1 \mathrm{~mm}$ de largo, curvados, ligeramente comprimidos, casi hialinos, con una vena longitudinal más oscura; anteras globosas, bitecas, pardo oscuras. Ovario ovoide, pardo oscuro; estilo $c a .1 \mathrm{~mm}$ de largo, ventral y dorsalmente quillado; estigma con el labio inferior circular, el superior ligulado. Cápsulas 6-8 $\mathrm{mm}$ de largo, angostamente ovadas, lisas, tumescentes, dehiscentes por una fisura longitudinal, ventral, ligeramente engrosada. Semillas numerosas, ca. 0,7$0,8 \mathrm{~mm}$ de largo, angostamente fusiformes, tenuemente estriadas longitudinalmente, áureo-amarillas, brillantes.

Paratipos. Cartago: Localidad típica, 5 sept 2003 (fl), J. Gómez-Laurito 14088, Diego Salazar et al. (USJ); 18 jun 2005 (botones florales), J. Gómez-Laurito 14469, 


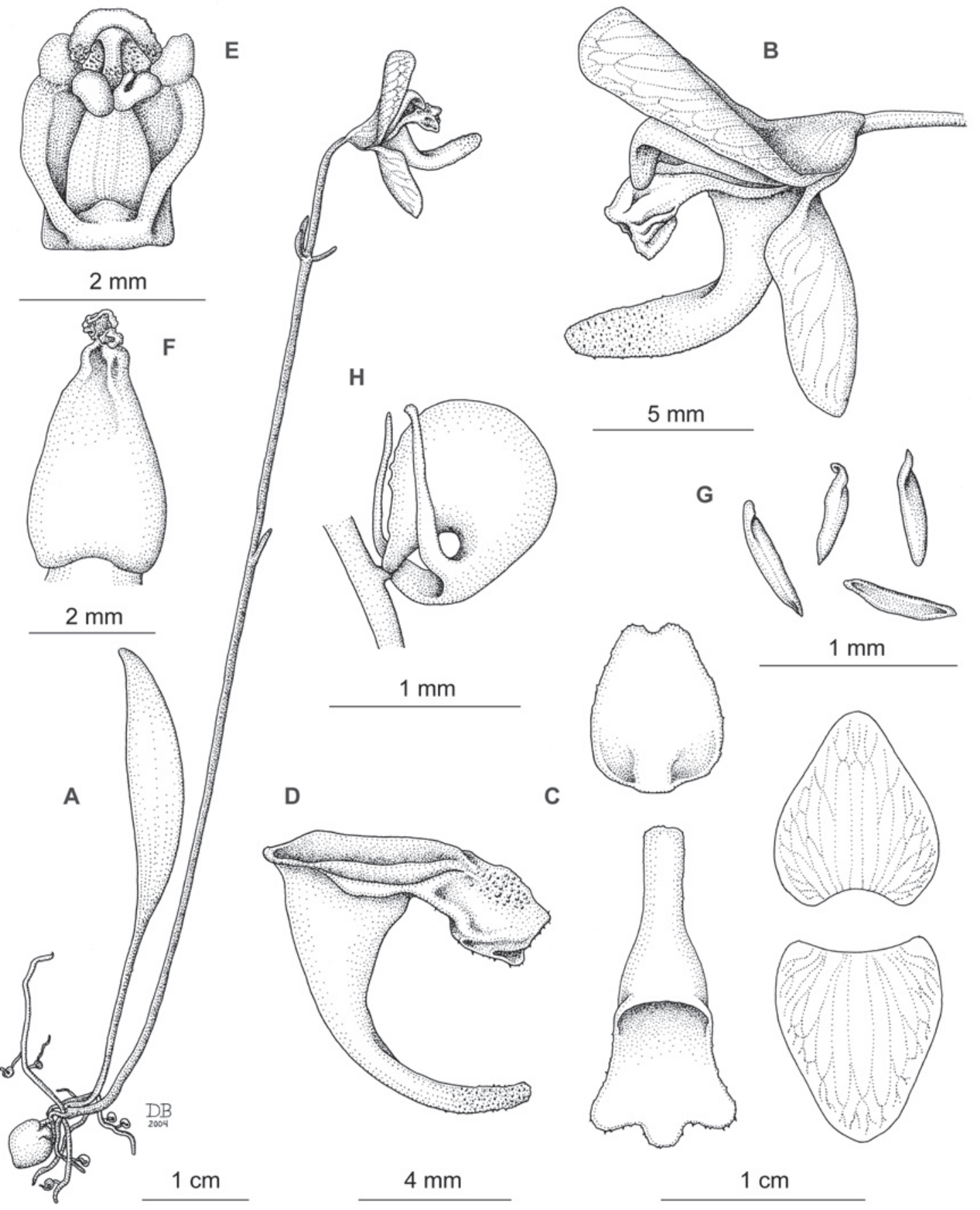

Fig. 1. Utricularia uxoris Gómez-Laur. A- Hábito de la planta. B- Flor. C- Labios superior e inferior y lóbulos del cáliz. D- Espuela. E- Androceo y gineceo. F- Cápsula. G- Semillas. H- Trampa. Testigo: J. Gómez-Laurito et al. 14360 (USJ). 
Diego Salazar, Jorge Carmona \& María G. Gei (USJ); un duplicado floreció en cultivo en Guadalupe, San José, ca. $1150 \mathrm{~m}, 15$ ago 2005 .

DistribuCión Y HÁBITAT. Hasta el presente esta especie es conocida solamente de la localidad típica. De acuerdo a Gómez \& Herrera (1993), esta región pertenece a la unidad biótica Subtropical, tropical, muy húmeda, sin estación seca. En esta Reserva son comunes grandes Ficus spp. (Moraceae), Protium sp. (Burseraceae), Matudaea trinervia Lundell (Hamamelidaceae), Alfaroa manningii J. León (Juglandaceae), Abarema idiopoda (S.F. Blake) Barn. \& Grimes (Mimosaceae), Ticodendron incognitum Gómez-Laur. \& L.D. Gómez (Ticodendraceae) y Cassipourea elliptica (Sw.) Poit. (Rhizophoraceae), entre otros.

Etimología. Speciem pulchram novam carae Ingridiae uxoris cordialiter dico, hoc modo vicesimum quintum anniversarium nuptiarum laetus commemoro.

Utricularia uxoris es una especie muy distintiva; a simple vista defiere de las especies costarricenses de la sección Orchidioides por poseer flores con cáliz y corola verdes, con la espuela blanca. Por el contrario, el resto de las especies poseen flores conspicuamente blancas, color malva o rojas y con una mácula amarilla. De U. jamesoniana Oliver difiere, además, por presentar esta especie los lóbulos del labio inferior profundamente divididos, mientras que en $U$. uxoris son apenas insinuados (0,5 mm). Utricularia endresii Rchb.f., $U$. praetermissa P. Taylor y U. unifolia Ruiz \& Pav. son plantas mucho más robustas, principalmente terrestres, con flores y hojas de mayor tamaño, y con las corolas en ambas superficies y márgenes provistas de pelos glandulares estipitados, densamente en $U$. endresii y esparcidos en las otras dos. En contraste, U. uxoris es siempre una epífita pequeña y sus corolas son completamente glabras. De las restantes especies, hasta el presente halladas solamente en Sudamérica, se distingue así: de $U$. campbelliana Oliver en que ésta tiene sus partes vegetativas cubiertas por glándulas sésiles o semi-inmersas y sus flores son rojo anaranjado con una mancha amarilla en la base del labio inferior. De $U$. quelchi N.E. Br. en que ésta tiene casi todas sus partes vegetativas cubiertas por una mezcla de glándulas globosas y sésiles o cortamente cilíndricas; además, sus flores son rojas o rosadas con una mancha amarilla en la base del labio inferior. De $U$. buntingiana P. Taylor en que ésta tiene las trampas cubiertas con numerosos pelos sésiles, globosos, y flores lavanda o malva pálido con una mancha amarilla en el labio inferior.

Agradecimientos. A Diego Salazar, Jorge Carmona y María G. Gei por su interés y su ayuda en el campo, a Diego Bogarín por la excelente ilustración y a Alberto Chaves, de la Reserva El Copal, por sus atenciones.

\section{LiterATURA CITADA}

Crow, G.E. 1992. The genus Utricularia (Lentibulariaceae) in Costa Rica. Brenesia 38: 1-18.

Taylor, P. 1989. The genus Utricularia: a taxonomic monograph. Kew Bull. Add. Ser. 14: 418-429. 
